\title{
Assignment for the Infrared Spectrum of Solid Sodium Propionate from Low-Temperature Measurements in Combination with ${ }^{13} \mathrm{C}$ Isotopic Shifts
}

\author{
Masato Kakihana and Tadashi Nagumo \\ Department of Chemistry, The National Defense Academy, Yokosuka, Japan
}

Z. Naturforsch. 42 a, 477-484 (1987); received January 14, 1987

The infrared spectra of $\mathrm{CH}_{3} \mathrm{CH}_{2} \mathrm{COONa}$ and its ${ }^{13} \mathrm{C}$-labeled modifications $\left(1-{ }^{13} \mathrm{C}, 2-{ }^{13} \mathrm{C}\right.$, and ${ }^{3-}{ }^{13} \mathrm{C}$ ) suspended in $\mathrm{KBr}$ disks were measured in the region $4000-200 \mathrm{~cm}^{-1}$ at room temperature and liquid nitrogen temperature. Overlapping complex band contours appeared in some regions of the room temperature spectrum, most notably in the region $1500-1350 \mathrm{~cm}^{-1}$, where 5 fundamentals having contributions from the methyl deformation, methylene bending, and carboxylate stretching modes should occur. In contrast to this, excellent resolution was reached at the low temperature, from which all 22 fundamentals expected in the whole spectral region investigated were detected. A complete assignment of the fundamentals is proposed mainly on the basis of the characteristic isotopic shifts of the three ${ }^{13} \mathrm{C}$ substituted sodium propionate species. A fair number of the fundamentals were found to feature coupled modes having contributions from several group vibrations.

\section{Introduction}

Propionate ion is important not only in organic chemistry but also in inorganic chemistry as one of the simplest ligands forming metal complexes. To our knowledge, however, no assignment for the infrared spectrum of the ionized form of propionic acid [1] has been reported so far. In recent papers [2-4] relating to the vibrational analyses of sodium acetate and pyruvate, we have shown that i) lowtemperature infrared spectra make it possible to clarify regions of the spectra which are overlapped at room temperature, and thus to locate the fundamental frequencies without ambiguity, and that ii) the frequencies from heavy atom isotope $\left({ }^{13} \mathrm{C},{ }^{18} \mathrm{O}\right.$, etc.) labeled modifications rather than D-labeled species allow for more reliable assignments of the fundamentals.

In the present work, the infrared spectra of $\mathrm{CH}_{3} \mathrm{CH}_{2} \mathrm{COONa}$ (parent species), $\mathrm{CH}_{3} \mathrm{CH}_{2}{ }^{13} \mathrm{COONa}$ $\left(1-{ }^{13} \mathrm{C}\right), \mathrm{CH}_{3}{ }^{13} \mathrm{CH}_{2} \mathrm{COONa}\left(2-{ }^{13} \mathrm{C}\right)$, and ${ }^{13} \mathrm{CH}_{3} \mathrm{CH}_{2}-$ COONa $\left(3-{ }^{13} \mathrm{C}\right)$ were measured at 80 and $290 \mathrm{~K}$. Detailed profiles of the low-temperature spectra are given in order to demonstrate their great advantage in reaching excellent resolution. Vibrational assignments are presented for all the fundamentals observed in the spectral region $4000-200 \mathrm{~cm}^{-1}$ with the aid of the ${ }^{13} \mathrm{C}$ shifts of the fundamentals.

Reprint requests to Dr. M. Kakihana, Department of Chemistry, The National Defense Academy, Hashirimizu 1-10-20, Yokosuka 239, Japan.

\section{Experimental}

Potassium bromide and $\mathrm{CH}_{3} \mathrm{CH}_{2} \mathrm{COONa}$ were obtained commercially (E. Merck Co. Ltd., Darmstadt). The ${ }^{13} \mathrm{C}$-enriched modifications of sodium propionate were purchased from Merck Sharp and Dohme Canada Ltd. with $99 \%{ }^{13} \mathrm{C}$ isotopic purity for $1-{ }^{13} \mathrm{C}$ and with $90 \%$ for 2 and $3-{ }^{13} \mathrm{C}$. The handling of the samples and the preparation of $\mathrm{KBr}$ disks were as described in [2]. The infrared spectra were measured in the frequency regions of $4000-450 \mathrm{~cm}^{-1}$. and $450-200 \mathrm{~cm}^{-1}$ by using a Bruker IFS-113v FT-IR spectrometer with a resolution of $0.5 \mathrm{~cm}^{-1}$ and a Jasco Model A-702 spectrometer with slit program $\mathrm{N}$ (spectral resolution $2.5 \mathrm{~cm}^{-1}$ ), respectively. Liquid nitrogen cryostats with KRS-5 windows, Model CF-1104 (Oxford Instrument) and Model TM-1-511 (Cryogenic Research Laboratory), were used for the low-temperature measurements. The band frequencies lying in the region $450-200 \mathrm{~cm}^{-1}$ were calibrated against the standard absorption bands of gaseous $\mathrm{H}_{2} \mathrm{O}$ [5].

\section{Results and Discussion}

The great advantage of measuring spectra at low temperature is demonstrated for the parent species in Figs. 1 and 2 covering the spectral regions $3040-2880 \mathrm{~cm}^{-1}$ and $1700-250 \mathrm{~cm}^{-1}$, respectively. The $v_{2}$ band in Fig. 1 and the $v_{5}, v_{6}$, and $v_{18}$ bands in 


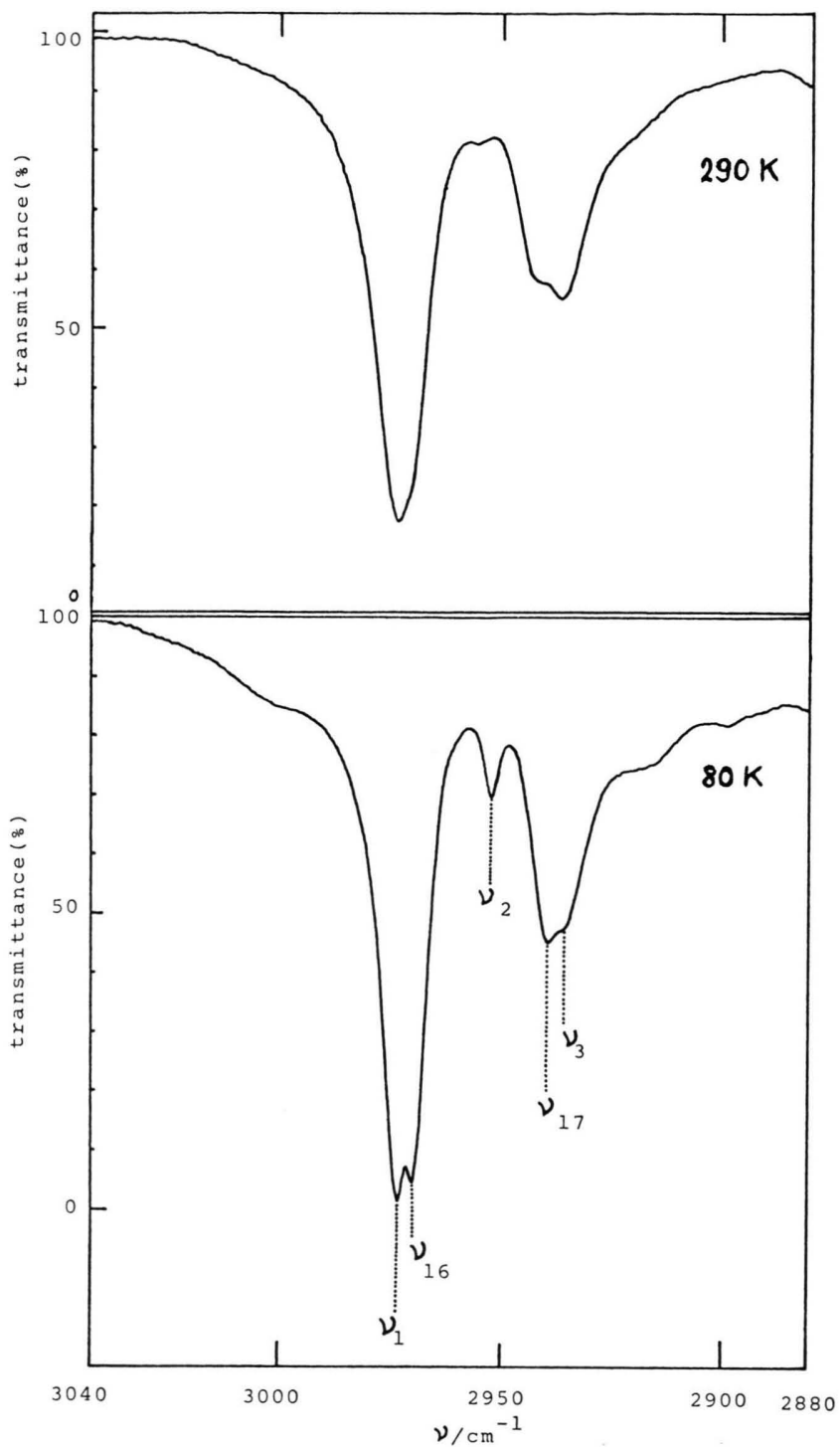

Fig. 1. Characteristic absorption bands due to $\mathrm{CH}_{3}$ - and $\mathrm{CH}_{2}$-stretching modes of $\mathrm{CH}_{3} \mathrm{CH}_{2} \mathrm{COONa}$ at 80 (below) and 290 (above) $\mathrm{K} ; 0.35 \mathrm{mg}$ of sample suspended in $150 \mathrm{mg}$ of $\mathrm{KBr}$. The symbols $v_{i}(i=1-3,16,17)$ correspond to those given in Table 1 .

Fig. 2, which were hardly discernible in the room temperature spectra, clearly showed up in the low temperature spectra. Such a sharpening effect is also seen for the $v_{19}, v_{22}$ and $v_{15}$ bands in Figure 2. Some of the lines at $80 \mathrm{~K}$ consist of two or more individual absorption lines. These lines presumably result from different crystal sites of sodium propionate. This interpretation is supported by an often similar structure of the corresponding absorption lines in
${ }^{13} \mathrm{C}$-labeled modifications of sodium propionate. Low temperature spectra are used throughout in this paper for the identification of the absorption lines.

In the present vibrational assignments, all the isotopic species concerned are assumed to belong a symmetry point group $\mathrm{C}_{\mathrm{s}}$ in which the vibrational representation has the form $15 A^{\prime}+9 A^{\prime \prime}$. Since the methyl and $\mathrm{CO}_{2}$ torsional $A^{\prime \prime}$ modes are expected to be observed in a low frequency region (less than $200 \mathrm{~cm}^{-1}$ ), they were not investigated in this paper. The fundamental frequencies observed at $80 \mathrm{~K}$, along with their proposed assignments, are listed in Table 1. The initial assignments of the fundamentals were carried out on the basis of the qualitative empirical rules available [6] and of comparisons with the vibrational assignments on related molecules such as sodium acetate [3], pyruvate [4], and propane [7]. The present ${ }^{13} \mathrm{C}$ isotopic shifts of the fundamentals are quite useful to assess the proposed assignments as indicated below.

\section{(1) CH-stretching region}

In the region of $3000 \mathrm{~cm}^{-1}$, a total of 5 fundamentals are expected to be observed; three of them are classified as $\mathrm{CH}_{3}$ stretching modes, the others as $\mathrm{CH}_{2}$ stretching vibrations. An expanded section of the low temperature spectrum for the parent species is shown in Fig. 3, together with the corresponding spectra for the ${ }^{13} \mathrm{C}$-labeled modifications. Going from the high frequency side to the lower frequency side, one finds a strong intensity band with a doublet structure ( $v_{1}$ and $v_{16}$ ), a weak intensity band $\left(v_{2}\right)$, and a medium intensity band $\left(v_{17}\right)$ with a shoulder $\left(v_{3}\right)$ at lower frequency (see Figure $3 \mathrm{a}$ ). The doublet could be assigned to the near degenerate antisymmetric $\mathrm{CH}_{3}$ stretching modes, since the ${ }^{13} \mathrm{C}$-substitution at the methyl carbon caused a significant lower frequency shift $\left(\mathrm{ca} .8 \mathrm{~cm}^{-1}\right)$ of the band in question (see Figure $3 \mathrm{~d}$ ). The $v_{2}$ and $v_{17}$ bands observed at 2952.5 and $2940.0 \mathrm{~cm}^{-1}$ for the parent species could be due to the symmetric and antisymmetric stretching motions of the $\mathrm{CH}_{2}$ group. The corresponding fundamentals for the $2-{ }^{13} \mathrm{C}$ labeled modification were found at 2943.5 and $2933.3 \mathrm{~cm}^{-1}$ with lower frequency shifts (see Figure $3 \mathrm{c}$ ). The remaining symmetric $\mathrm{CH}_{3}$ stretching fundamental for the parent species is submerged under the $v_{17}$ band assigned to the $\mathrm{CH}_{2}$ antisymmetric stretching mode, and it was observed only as 


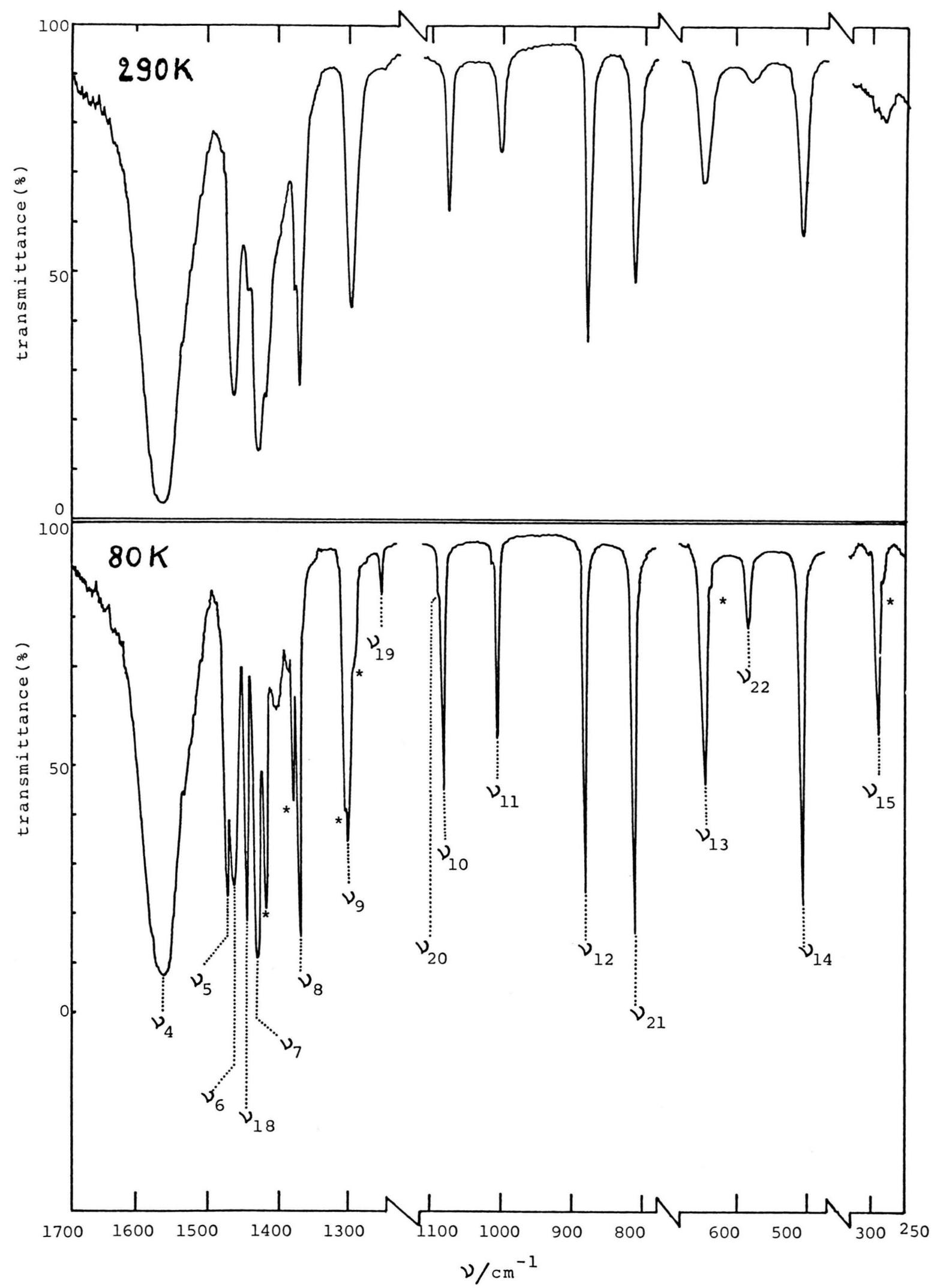

Fig. 2. Selected regions of the infrared spectrum of $\mathrm{CH}_{3} \mathrm{CH}_{2} \mathrm{COONa}$ at 80 (below) and 290 (above) $\mathrm{K}$; $0.35 \mathrm{mg}$ of sample suspended in $150 \mathrm{mg}$ of $\mathrm{KBr}$. For the symbols $v_{i}(i=4-22)$ see the notations in Table 1 . Bands in the spectrum at $80 \mathrm{~K}$ marked by an asterisk represent factor group splittings. 


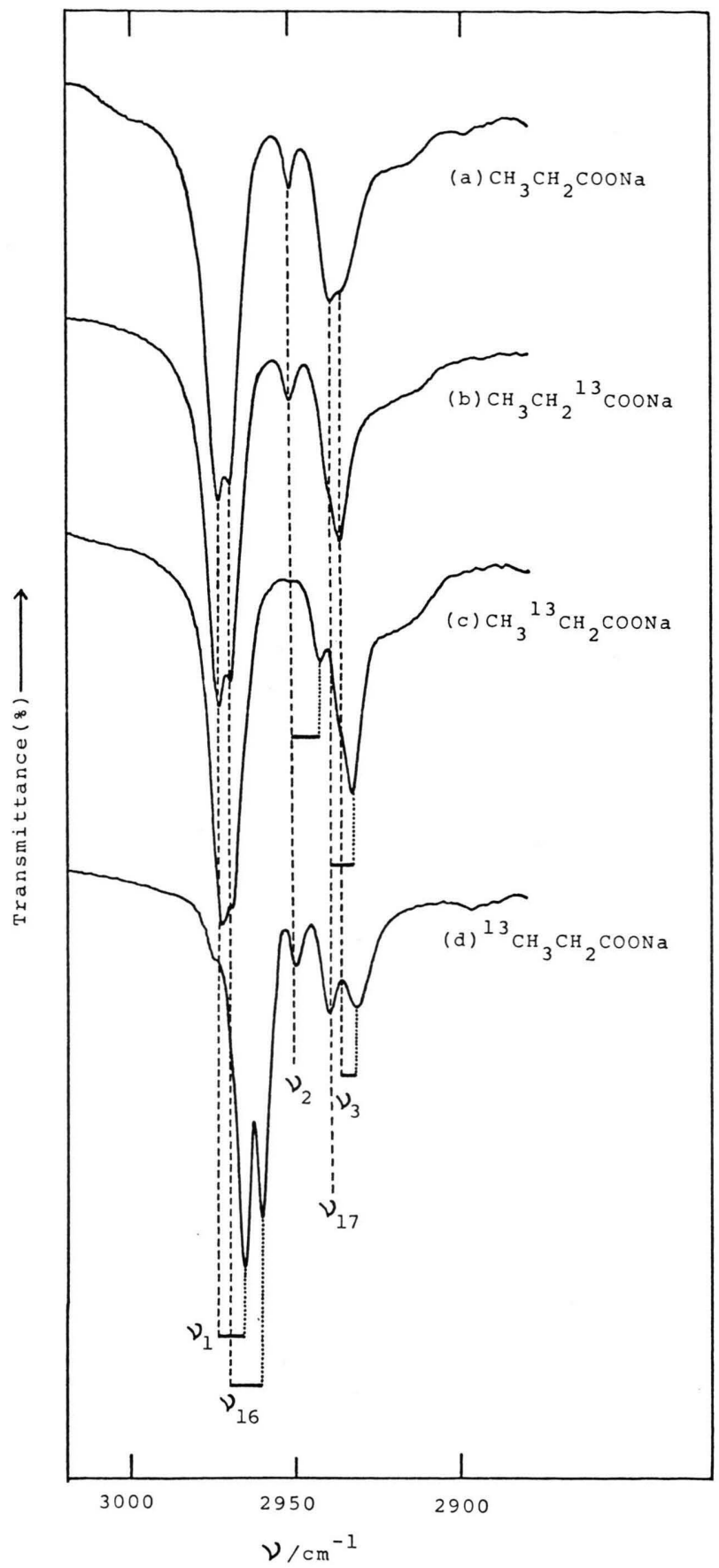

Fig. 3. $\mathrm{CH}_{3}$ - and $\mathrm{CH}_{2}$-stretching region of the spectra of $\mathrm{CH}_{3} \mathrm{CH}_{2} \mathrm{COONa}$ (a) $\mathrm{CH}_{3} \mathrm{CH}_{2}{ }^{13} \mathrm{COONa}$ (b), $\mathrm{CH}_{3}{ }^{13} \mathrm{CH}_{2} \mathrm{COONa}$ (c), and ${ }^{13} \mathrm{CH}_{3} \mathrm{CH}_{2} \mathrm{COONa}$ (d) at $80 \mathrm{~K}$; $0.35 \mathrm{mg}$ of sample suspended in $150 \mathrm{mg}$ of $\mathrm{KBr}$. Broken and dotted lines indicate positions of fundamentals for the parent and ${ }^{13} \mathrm{C}$-labeled species, respectively. Horizontal lines connecting broken and dotted lines represent magnitudes of ${ }^{13} \mathrm{C}$-shifts of fundamentals. For symbols $v_{i}$, see the notations given in Table 1 . a shoulder $\left(v_{3}\right)$ at about $2937 \mathrm{~cm}^{-1}$. The ${ }^{13} \mathrm{C}$-substitution at the methyl carbon caused a lower frequency shift $\left(\mathrm{ca} .8 \mathrm{~cm}^{-1}\right.$ ) of the $v_{3}$ band, so that the fundamental due to the $\mathrm{CH}_{3}$ symmetric stretching mode for the $3-{ }^{13} \mathrm{C}$ labeled modification was separately observed from the $v_{17}$ band as shown in Figure $3 \mathrm{~d}$.

\section{(2) $\mathrm{CO}_{2}$-stretching and $(\mathrm{HCH})$-bending region}

The band observed at $1563.2 \mathrm{~cm}^{-1}\left(v_{4}\right)$ for the parent species is very intense as shown in Figure 2. The $v_{4}$ band shifts by ca. $40 \mathrm{~cm}^{-1}$ upon ${ }^{13} \mathrm{C}$-substitution of the carboxylate group, whereas the same band has a high degree of the antisymmetric $\mathrm{CO}_{2}$ of the methylene and methyl groups (see $v_{4}$ in Table 1). The intensity of the band and the result of the ${ }^{13} \mathrm{C}$ isotopic shift strongly suggest that the $v_{4}$ band has a high degree of the antisymmetric $\mathrm{CO}_{2}$ stretching character. In the low temperature spectrum for the parent species all 7 fundamentals $\left(5 A^{\prime}+2 A^{\prime \prime}\right)$ expected in the spectral region 1500 to $1200 \mathrm{~cm}^{-1}$ may be localized as shown in Figure 4. Of these, the assignment of the fundamental due to a symmetric $\mathrm{CO}_{2}$ stretching motion is straightforward; the $v_{7}$ band at $1428.6 \mathrm{~cm}^{-1}$ for the parent species undergoes a large frequency shift (ca. $18 \mathrm{~cm}^{-1}$ ) only in the IR spectrum of the $1-{ }^{13} \mathrm{C}$ labeled modification, and therefore the $v_{7}$ band is assignable to the symmetric $\mathrm{CO}_{2}$ stretching mode.

The three distinct bands observed at $1471.2\left(v_{5}\right)$, $1461.4\left(v_{6}\right)$, and $1442.4\left(v_{18}\right) \mathrm{cm}^{-1}$ for the parent molecule may be assigned to two antisymmetric $\mathrm{CH}_{3}$ deformation modes and one $\mathrm{CH}_{2}$ bending mode. However, the results of the ${ }^{13} \mathrm{C}$-isotopic shifts suggest that the three normal modes are strongly intermixed or coupled with several group modes. Since the $v_{5}$ and $v_{6}$ bands are significantly shifted by the ${ }^{13} \mathrm{C}$-substitution of the $\mathrm{CO}_{2}$ and $\mathrm{CH}_{2}$ carbon atoms, they may be assigned to coupling modes of the antisymmetric $\mathrm{CH}_{3}$ deformation $\left(A^{\prime}\right), \mathrm{CH}_{2}$ bending, and $\mathrm{CO}_{2}$ symmetric stretching vibrations. The remaining $v_{18}$ band slightly shifts upon ${ }^{13} \mathrm{C}$ substitution of the $\mathrm{CO}_{2}$ and $\mathrm{CH}_{2}$ groups and is tentatively assigned to the antisymmetric $\mathrm{CH}_{3}$ deformation mode $\left(A^{\prime \prime}\right)$. It is noteworthy that the three bands shift only by ca. $1 \mathrm{~cm}^{-1}$ upon ${ }^{13} \mathrm{C}$-substitution of the $\mathrm{CH}_{3}$ group. Such a feature has been found in the spectra of methylnitrite [8], thioacetamide [9], and pyruvic acid [10], where the bands assigned to 
Table 1. Observed frequencies and tentative assignments for the fundamentals of four isotopic species of sodium propionate at $80 \mathrm{~K}$.

\begin{tabular}{|c|c|c|c|c|c|c|}
\hline \multirow{2}{*}{$\begin{array}{l}\text { Represen- } \\
\text { tation } \\
\mathrm{C}_{\mathrm{s}}\end{array}$} & \multirow[t]{2}{*}{ Notation } & \multirow[t]{2}{*}{ Approximate description } & $\mathrm{CH}_{3} \mathrm{CH}_{2} \mathrm{COONa}$ & $((1-): \mathrm{COO}$ & $(2-): \mathrm{CH}_{2}$. & $\left.(3-): \mathrm{CH}_{3}.\right)$ \\
\hline & & & parent & $1-{ }^{13} \mathrm{C}$ & $2-{ }^{13} \mathrm{C}$ & $3-{ }^{13} \mathrm{C}$ \\
\hline \multirow[t]{17}{*}{$A^{\prime}$} & $v_{1}$ & asym $\mathrm{CH}_{3}$ str. & 2973.5 & 2973.1 & 2972.4 & 2966.3 \\
\hline & $v_{2}$ & sym $\mathrm{CH}_{2}$ str. & 2952.5 & 2952.6 & 2943.5 & 2950.1 \\
\hline & $v_{3}$ & sym $\mathrm{CH}_{3}$ str. & $2937^{\mathrm{a}}$ & 2937.4 & $2937^{a}$ & 2932.4 \\
\hline & $v_{4}$ & asym $\mathrm{CO}_{2}$ str. & 1563.2 & 1523.7 & 1563.7 & 1563.7 \\
\hline & $v_{5}$ & asym $\mathrm{CH}_{3}$ deform. + & 1471.2 & 1465.6 & 1468.5 & 1470.2 \\
\hline & $v_{6}$ & $\mathrm{CH}_{2}$ sciss. + sym $\mathrm{CO}_{2}$ str. & 1461.4 & 1454.0 & 1453.5 & 1460.8 \\
\hline & $v_{7}$ & sym $\mathrm{CO}_{2}$ str. & 1428.6 & 1410.4 & 1428.7 & 1429.1 \\
\hline & & & $1417^{b}$ & $1421,1402^{b}$ & $1414^{b}$ & $1416^{b}$ \\
\hline & $v_{8}$ & sym $\mathrm{CH}_{3}$ deform. & 1369.1 & $1367.7^{\mathrm{c}}$ & 1368.4 & 1360.2 \\
\hline & & & $1376^{\mathrm{b}}$ & & $1375^{\mathrm{b}}$ & $1367^{b}$ \\
\hline & $v_{9}$ & $\mathrm{CH}_{2}$ wag. & $1301.4^{\mathrm{c}}$ & $1298.4^{c}$ & 1286.5 & $1299.6^{c}$ \\
\hline & $v_{10}$ & $\begin{array}{l}\text { in-plane } \mathrm{CH}_{3} \text { rock }+ \\
\mathrm{CH}_{3}-\mathrm{C} \text { str. }\end{array}$ & 1077.7 & 1077.7 & 1061.8 & 1067.3 \\
\hline & $v_{11}$ & $\mathrm{CH}_{3}-\mathrm{C}$ str. (asym CCC str.) & 1009.9 & 1000.0 & 994.5 & 995.6 \\
\hline & $v_{12}$ & $\mathrm{CO}_{2}-\mathrm{C}$ str. (sym CCC str.) & 881.4 & 874.9 & 879.5 & 879.3 \\
\hline & $v_{13}$ & $\mathrm{CO}_{2}$ bend + asym CCC str. & 646.7 & 646.8 & 637.2 & 646.8 \\
\hline & $v_{14}$ & $\begin{array}{l}\text { in-plane } \mathrm{CO}_{2} \text { rock }+ \\
\text { sym CCC str. }\end{array}$ & 507.4 & 505.1 & 505.8 & 502.7 \\
\hline & $v_{15}$ & CCC bend & 291.5 & 290.8 & 291.2 & 289.8 \\
\hline \multirow[t]{7}{*}{$A^{\prime \prime}$} & $v_{16}$ & asym $\mathrm{CH}_{3}$ str. & 2970.2 & 2970.2 & 2970.0 & 2960.7 \\
\hline & $v_{17}$ & asym $\mathrm{CH}_{2}$ str. & 2940.0 & $2940^{\mathrm{a}}$ & 2933.3 & 2940.0 \\
\hline & $v_{18}$ & asym $\mathrm{CH}_{3}$ deform. & 1442.4 & 1438.6 & 1438.8 & 1441.5 \\
\hline & $v_{19}$ & $\begin{array}{l}\mathrm{CH}_{2} \text { twist }+ \text { out-of-plane } \\
\mathrm{CH}_{3} \text { rock }\end{array}$ & 1250.4 & 1248.4 & 1249.8 & 1245.4 \\
\hline & $v_{20}$ & $\begin{array}{l}\text { out-of-plane } \mathrm{CH}_{3} \text { rock }+ \\
\mathrm{CH}_{2} \text { twist or rock }\end{array}$ & $1080^{\mathrm{a}}$ & $1080^{\mathrm{a}}$ & 1071.4 & 1075.9 \\
\hline & $v_{21}$ & $\mathrm{CH}_{2}$ rock & 812.9 & 805.0 & 810.5 & 811.7 \\
\hline & $v_{22}$ & out-of-plane $\mathrm{CO}_{2}$ rock & 584.9 & 576.4 & 583.9 & 584.8 \\
\hline
\end{tabular}

a Shoulders.

b Minor components resulting from factor-group splittings.

c Averaged values of factor-group doublets of similar intensity.

the methyl antisymmetric deformation modes experience downward shifts of only about $2 \mathrm{~cm}^{-1}$ upon ${ }^{13} \mathrm{C}$-substitution of the methyl groups.

In contrast to the $v_{5}, v_{6}$, and $v_{18}$ bands, the $v_{8}$ band observed at $1369.1 \mathrm{~cm}^{-1}$ for the parent species undergoes a significant shift to $1360.2 \mathrm{~cm}^{-1}$ upon ${ }^{13} \mathrm{C}$-substitution of the $\mathrm{CH}_{3}$ group. Thus, by analogy with the $\mathrm{CH}_{3}$ deformational property of sodium acetate [3] and pyruvate [4], the $v_{8}$ band can be reasonably assigned to the symmetric $\mathrm{CH}_{3}$ deformation mode.

The $v_{9}$ band observed at $1301.4 \mathrm{~cm}^{-1}$ for the parent species, which shifts to $1286.5 \mathrm{~cm}^{-1}$ upon ${ }^{13} \mathrm{C}$-substitution of the $\mathrm{CH}_{2}$ group, may be due to a $\mathrm{CH}_{2}$ wagging motion. The weak $v_{19}$ band centered at $1250.4 \mathrm{~cm}^{-1}$ is tentatively assigned to a $\mathrm{CH}_{2}$ twisting mode, however a significant methyl ${ }^{13} \mathrm{C}$ shift $\left(5 \mathrm{~cm}^{-1}\right)$ of the $v_{19}$ band suggests considerable coupling of this vibration to an out-of-plane rocking mode of the $\mathrm{CH}_{3}$ group ( $v_{20}$, discussed later).

\section{(3) Fingerprint region, $1200-200 \mathrm{~cm}^{-1}$}

The main problem of the assignment in this region, in which $6 A^{\prime}+3 A^{\prime \prime}$ fundamentals are to be expected, focuses on two methyl rocking and two skeletal CC stretching modes. An expanded section of the low-temperature spectra for the parent and its three ${ }^{13} \mathrm{C}$-isotopic species is shown in Fig. 5 in the frequency region $1100-860 \mathrm{~cm}^{-1}$. One strong band 


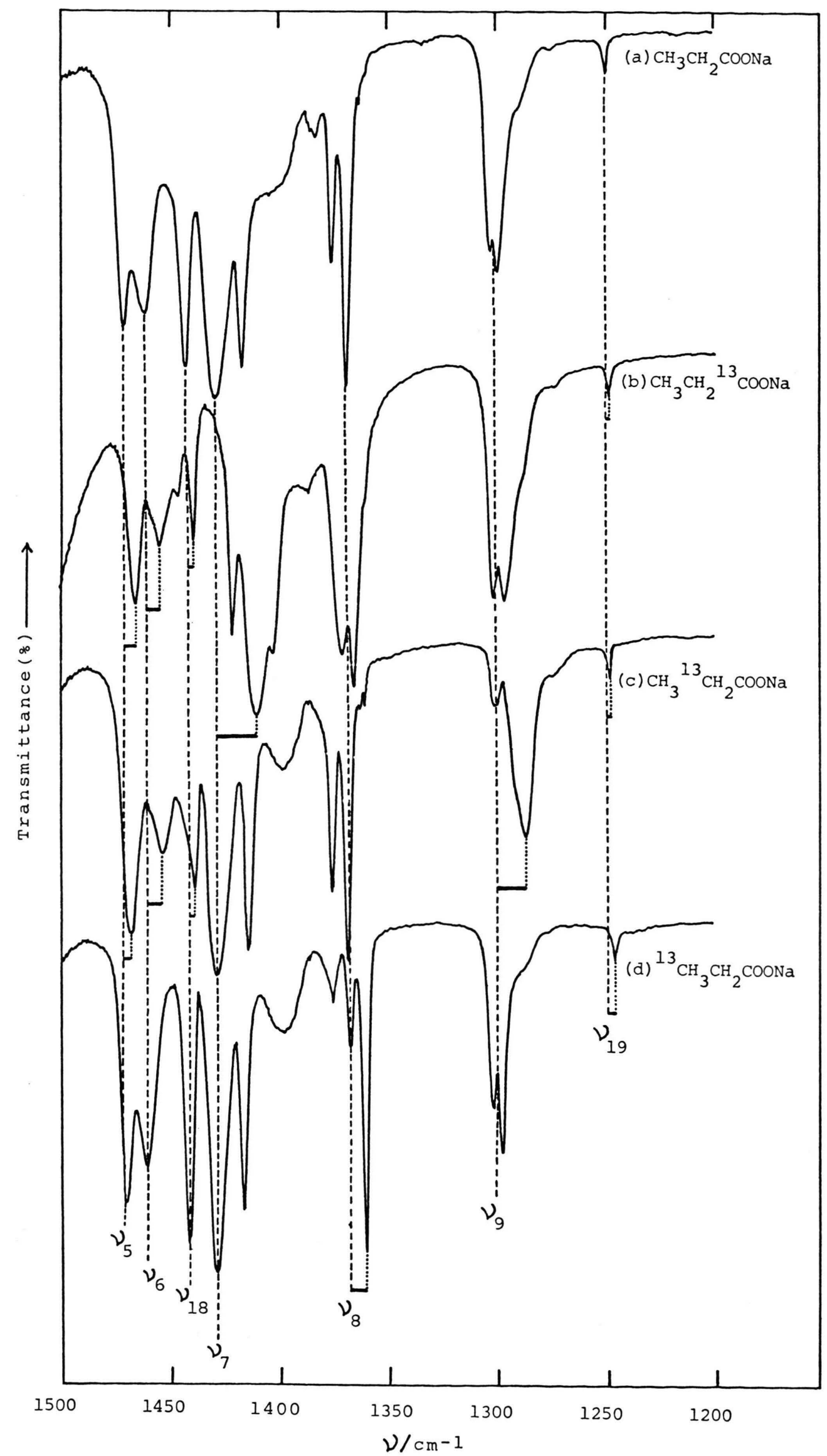

Fig. 4. $\mathrm{CO}_{2}$-stretching, $\mathrm{CH}_{3}$ - and $\mathrm{CH}_{2}$-bending region of the spectra of $\mathrm{CH}_{3} \mathrm{CH}_{2} \mathrm{COONa}$ (a), $\mathrm{CH}_{3} \mathrm{CH}_{2}{ }^{13} \mathrm{COONa}$ (b), $\mathrm{CH}_{3}{ }^{13} \mathrm{CH}_{2} \mathrm{COONa}$ (c), and ${ }^{13} \mathrm{CH}_{3} \mathrm{CH}_{2} \mathrm{COONa}$ (d) at $80 \mathrm{~K}: 0.35 \mathrm{mg}$ of sample suspended in $150 \mathrm{mg}$ of $\mathrm{KBr}$. For broken. dotted, and horizontal lines, see Figure 3. For symbols $v_{i}$, see the notations given in Table 1. 


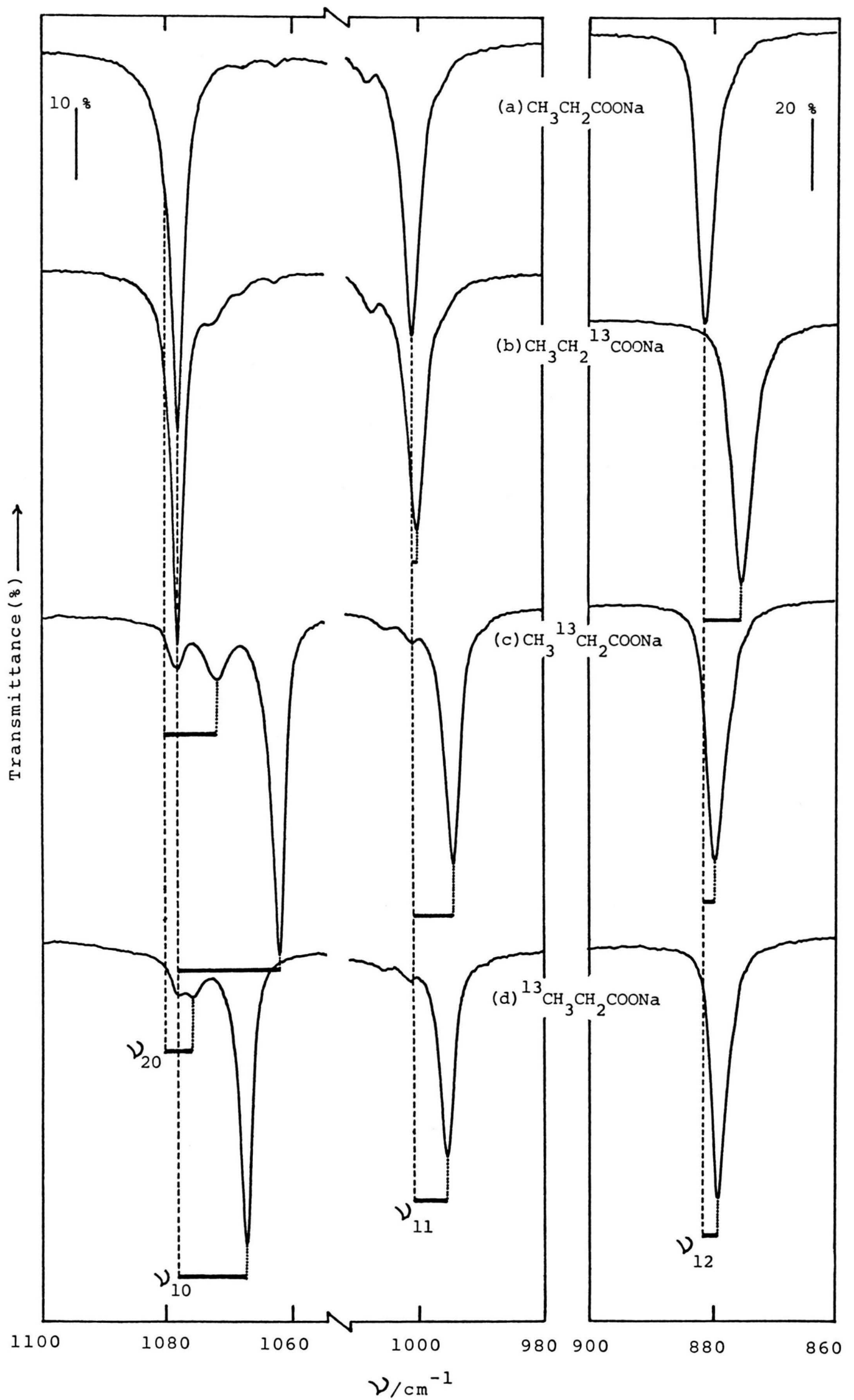

Fig. 5. Fingerprint region of the spectra of $\mathrm{CH}_{3} \mathrm{CH}_{2} \mathrm{COONa}$ (a), $\mathrm{CH}_{3} \mathrm{CH}_{2}{ }^{13} \mathrm{COONa}$ (b), $\mathrm{CH}_{3}{ }^{13} \mathrm{CH}_{2} \mathrm{COONa}$ (c), and ${ }^{13} \mathrm{CH}_{3} \mathrm{CH}_{2} \mathrm{COONa}$ (d) at $80 \mathrm{~K} ; 0.35 \mathrm{mg}$ of sample suspended in $150 \mathrm{mg}$ of $\mathrm{KBr}$. For broken, dotted, and horizontal lines, see Figure 3. For symbols $v_{i}$, see the notations given in Table 1 . Weak bands appearing in a higher frequency side of the spectra (c) and (d) are due to coexisting parent species. 
$\left(v_{10}\right)$ with a shoulder $\left(v_{20}\right)$ was observed at $1077.7 \mathrm{~cm}^{-1}$ for the parent species, which undergoes large shifts by $15.9 \mathrm{~cm}^{-1}$ and $10.4 \mathrm{~cm}^{-1}$ upon ${ }^{13} \mathrm{C}$-substitution of the $\mathrm{CH}_{2}$ and $\mathrm{CH}_{3}$ groups, respectively. Based on this observation of the ${ }^{13} \mathrm{C}$-shifts, the $v_{10}$ band can be assigned to a coupled mode having contributions from the in-plane $\mathrm{CH}_{3}$ rocking and $\mathrm{CH}_{3}-\mathrm{C}$ stretching vibrations. The large isotopic shifts of the $v_{10}$ band enable us to locate the $v_{20}$ bands at 1071.4 and $1075.9 \mathrm{~cm}^{-1}$ in the spectra of $2-$ and $3-{ }^{13} \mathrm{C}$ labeled modifications, respectively (see Fig. $5 \mathrm{c}$ and $5 \mathrm{~d}$ ). The $v_{20}$ band could be assigned to a coupled mode of the out-of-plane $\mathrm{CH}_{3}$ rocking and $\mathrm{CH}_{2}$ twist or rocking vibrations.

The $v_{11}$ and $v_{12}$ bands centered at 1000.9 and $881.4 \mathrm{~cm}^{-1}$ for the parent species were tentatively assigned to the $\mathrm{CH}_{3}-\mathrm{C}$ and $\mathrm{C}-\mathrm{CO}_{2}$ stretching modes, respectively, by taking into account the characteristic ${ }^{13} \mathrm{C}$-shifts of the fundamentals (see Fig. 5 and Table 1). The assignments of the remaining 5 fundamental bands to the descriptions given in Table 1 were made by comparison with the vibrational assignments of sodium acetate [3]

[1] B. Dupuy and C. Garrigou-Lagrange, J. Chim. Phys. 62, 1359 (1965).

[2] M. Kakihana, M. Kotaka, and M. Okamoto, J. Phys Chem. 86, 4385 (1982)

[3] M. Kakihana, M. Kotaka, and M. Okamoto, J. Phys, Chem. 87, 2526 (1983)

[4] M. Kakihana and M. Okamoto, J. Phys. Chem. 88, 1797 (1984).

[5] International Union of Pure and Applied Chemistry (IUPAC), Tables of Wavenumbers for the Calibration of Infrared Spectrometers"; Pergamon Press, New York 1977. and propane [7], and with the result of a microwave study for propionic acid reported by Stiefvater [11]. It should finally be noted that the vibrational descriptions given for the 5 fundamental bands are only qualitative in the sense that many of the normal modes may be strongly intermixed or coupled with several group modes.

\section{Conclusion}

In this paper, we have presented IR fundamental frequeny data for sodium propionate including its three ${ }^{13} \mathrm{C}$-substituted species. The fine structures of complex overlapping regions were revealed by measuring the spectra at liquid $\mathrm{N}_{2}$ temperature. The low temperature measurements combined with ${ }^{13} \mathrm{C}$ isotopic shifts have been demonstrated to be effective in elucidating vibrational assignments for some fundamentals of sodium propionate. The degree of coupling between several group modes has been clarified by taking into consideration the ${ }^{13} \mathrm{C}$-shifts of the fundamentals.

[6] L. J. Bellamy, The Infrared spectra of Complex Molecules-Advances in Infrared Group Frequencies, 2nd ed.; Chapman \& Hall, New York 1980, Vol. 2.

[7] R. A. R. Pearce and I. W. Levin, J. Chem. Phys. 70, 370 (1979).

[8] P. N. Ghosh and H. H. Günthard, Spectrochim. Acta 37 A, 1055 (1981)

[9] U. Anthoni, P. H. Nielsen, and D. H. Christensen, Spectrochim. Acta 41 A, 1327 (1985).

[10] H. Hollenstein, F. Akermann, and H. H. Günthard, Spectrochim. Acta 34A, 1041 (1978)

[11] O. L. Stiefvater, J. Chem. Phys. 62, 233 (1975) 